Research Paper

\title{
Overview of human resource in Japanese academic research institutes
}

\author{
Morio SHIBAYAMA \\ National Institute of Informatics
}

\begin{abstract}
After the Science Council of Japan published a report in 1992 promoting science activities for the 21st century, the science policy for human resource was roused among researchers in Japanese academic institutes. This paper intends to overview the recent conditions surrounding research personnel engaged in Japanese academic institutes. The author has taken a bibliographic approach to survey public science statistics and to process NII reports and databases. Based on these data, the author made an analysis of the human resources in Japanese academic research institutes and considered the tasks of science policy and the role of researchers.
\end{abstract}

\section{KEYWORDS}

Science policy, human resource, research activity, award, patent, joint research

\section{Introduction}

\subsection{Science Council report in 1992}

In 1992, the Science Council, the advisory body to the Minister of Education, Science, Sports and Culture of Japan, submitted a report on the "Comprehensive Promotion Measures for Science Research on the Brink of the 21st Century", and made a fundamental policy to promote academic research activities for this decade. The main goals outlined in the report are (1) the expansion of financial support for academic research activities, (2) the improvement of campus facilities and equipment, (3) to train graduate school students and to increase the number of personnel engaged in research institutes, (4) the construction of a world-wide information network, and (5) the promotion of performance in research organizations, as well as others. [1]

According to the report, academic research activities were defined as intellectual and creative contributions to all human cultures and societies, and it was clarified that researchers have the social responsibility to return benefits their research produced. For further societal development, and solutions for problems that were common all over the world, academic research activi-

Received August 10, 2005; Revised September 29, 2005; Accepted November 2, 2005.

shibayam@nii.ac.jp

DOI: $10.2201 /$ NiiPi.2006.3.4 ties would play important roles.

To promote academic research activities, it was necessary to improve the environments in which researches were carried out. The council emphasized on academic activities at universities, which were expected to keep an appropriate balance between education and research. To provide meaningful education and promote academic research, the council indicated the improvement of a level of research and providing more opportunities for younger researchers and women researchers to join research activities.

The improvement of facilities, research equipment, and information networks was moderately completed by financial support, but there remained the tasks of the researchers.

It is important to verify how the goals are attained and about what has been carried out by spontaneous efforts of institutes and researchers at the beginning of the 21 st century. In order to know this, it is necessary to review recent academic research activities. This paper analyzes the human resources from 1993 to 2003 and considers future tasks.

\subsection{Background of research condition}

According to the Statistics Bureau of the Japanese Government, [2] there were 757,000 researchers in total and 281,000 at universities \& colleges in 2003. Both of 


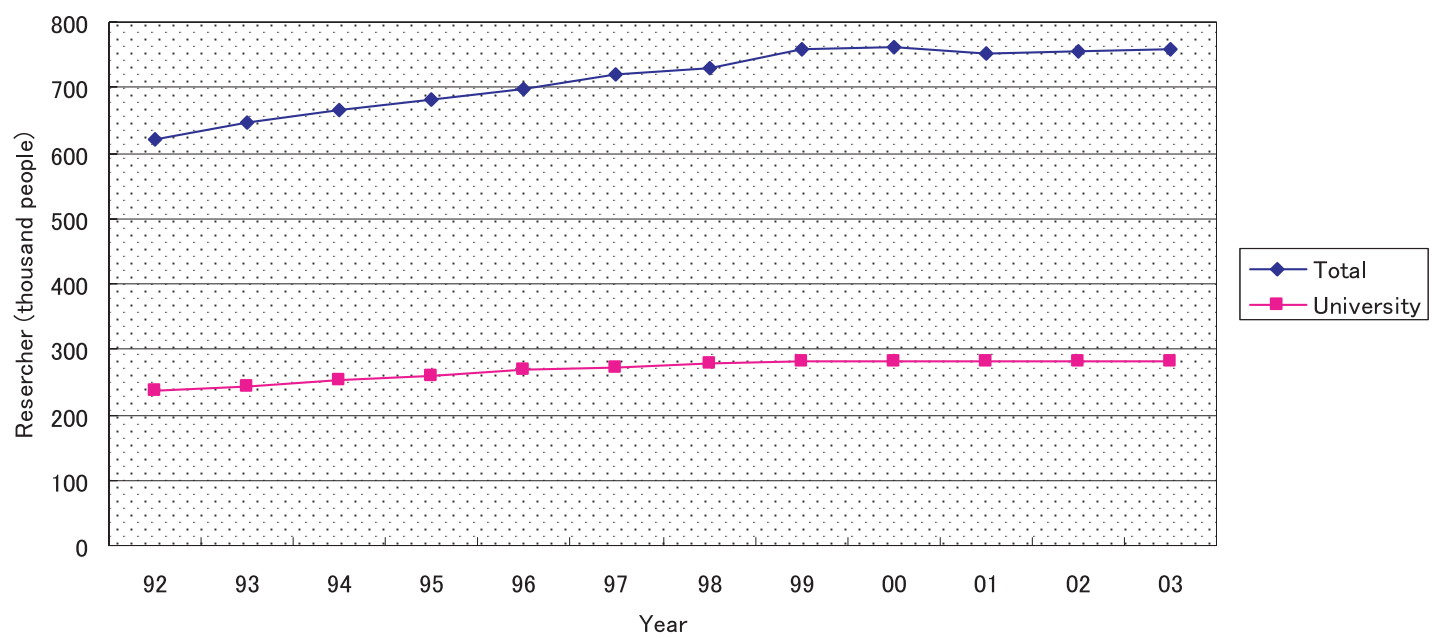

(Statistics Bureau, 2004)

Fig. 1 Researcher trends in total and at universities \& colleges.

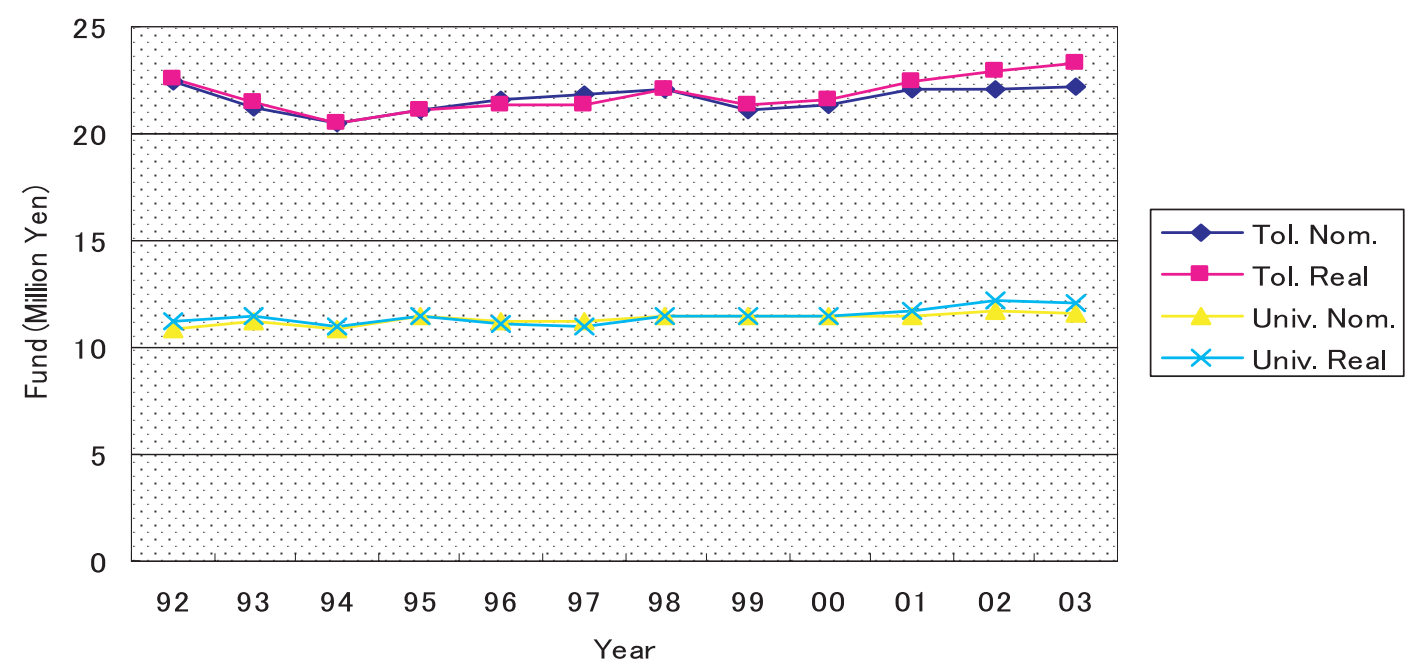

(Statistics Bureau, 2004)

Fig. 2 Research funds trend in total and at universities \& colleges.

these statistics have gradually increased by $14.8 \%$ and $13.1 \%$, respectively, in the resent decade. The category for total research institutes in Japan includes industrial corporations, public research institutes, governmental research institutes, universities, and colleges.

The number of researchers at universities \& colleges includes teaching staff, students in doctorial courses, and university hospital staff. This would appear to be a lager population in comparison to the researcher categories in foreign countries.

Research funds, as well as the number of researchers, are important indicators for the evaluation of research activities. Research funds per researcher have been constant, at around 22 million yen in total and 11 million yen at universities \& colleges. [2] Even if the price index is considered, there is a very small difference between the nominal term and real terms. Research funds at universities \& colleges are, on the whole, lower than those averaged for Japanese research institutes. It is concluded that the research funds per researcher has not raised over the past 10 years in Japanese academic research institutes. [17]-[20]

\section{Researchers in academic institutes from 1993 to 2003}

\subsection{Outlines}

NII has carried out a survey on the academic research activities from 1993, aimed at researchers in Japanese academic research institutes. Based on the results of the survey, NII has published reports and compiled a "Di- 
Table 1 Number of subjects and replies for 1995 survey.

\begin{tabular}{lrrrr}
\hline \multirow{2}{*}{ Research institutions } & \multicolumn{2}{c}{ No. of subjects } & \multicolumn{2}{c}{$\begin{array}{c}\text { No. of replies } \\
\text { (response rate) }\end{array}$} \\
\cline { 2 - 5 } & Institutions & Individuals & Institutions & Individuals \\
\hline University & 556 & 134,900 & $550(97.2 \%)$ & $106,837(79.2 \%)$ \\
\hline Junior college & 585 & 17,946 & $556(95.0 \%)$ & $17,001(94.6 \%)$ \\
\hline Technical college & 62 & 4,098 & $62(100.0 \%)$ & $4,098(99.6 \%)$ \\
\hline $\begin{array}{l}\text { Inter-university research } \\
\text { institute etc. }\end{array}$ & 20 & 1,247 & $19(95.0 \%)$ & $994(79.3 \%)$ \\
\hline $\begin{array}{l}\text { Ministry of Education } \\
\text { jurisdiction organization } \\
\text { etc. }\end{array}$ & 18 & 535 & $13(72.2 \%)$ & $436(81.5 \%)$ \\
\hline $\begin{array}{l}\text { Private sector scientific } \\
\text { research organization }\end{array}$ & 154 & 990 & $78(50.6 \%)$ & $929(93.5 \%)$ \\
\hline Total & 1,405 & 159,752 & $1,278(91.0 \%)$ & $130,295(81.6 \%)$ \\
\hline
\end{tabular}

rectory of Researchers" database. The database contains about 140,000 researchers in Japanese academic institutes. The author arranged these reports from that survey and researchers information for this study.

As outlines of the transition of the researchers' population from 1993 to 2003, this chapter shows a research organization classification, and the ratio for each research field, and women researchers, researchers with foreign names, and graduate students. Those items are based on a series of reports titled, "Situation of the Scientific Research Activities in Our Country: Results of Survey on Scientific research Activity" by NACSIS (former name of NII) and NII, covering from 1995 to 2003. [3]-[12] The items of institutes and individual researchers carried out in a 1995 survey are as follows: $<$ A $>$ Institutes

(1) Universities (National, Public, and Private)

(2) Junior colleges (National, Public, and Private)

(3) Technical colleges (National, Public, and Private)

(4) Inter-university Research institutes, The National Center for University Entrance Examinations and National Institution for Academic Degrees, and the Center for National University Finance (It is hereafter called an inter-university research institute etc.)

(5) The Ministry of Education, Science, Sports and Culture, the Agency for Cultural Affairs, and their jurisdiction/attached organization (hereafter called Ministry of Education jurisdiction organization etc.)

(6) The Ministry of Education jurisdiction private sector scientific research organization (hereafter called a private sector academic organization etc.)

$<\mathrm{B}>$ Individuals

Individuals working as educational personnel and the research staff (these personnel are hereafter called "re- searchers") on functional duty as of May 1, 1995 which belonged to the institutes presented above.

The total of 1,405 institutes and 159,752 individuals were the focus subjects of the survey. Among these, 1,278 institutes (a 91.0\% response rate) and 130,295 researchers (an $81.6 \%$ of response rate) replied.

The subjects of the survey were expanded for the 1998 survey. Since 1998, part-time-service researchers, postgraduate students in doctorial courses, staffs members who are beyond an assistants equivalent job of a university, the Japan Society for the Promotion of Science special researchers, and the Japan Society for the Promotion of Science researcher (research associate) were added to the subjects of the survey in 1995. In 2002, the investigator for this survey was shifted from NII to the Japan Science and Technology Agency. After this, the classification of fields and system of response contents of the survey were changed.

In 2001 the maximum number of useful samples was the data used. So this data was linked to the information of awards, patents and joint researches for the analysis of research output.

In total, it was 139,873 individuals (a $60.1 \%$ of response rate) from 1,377 institutes $(92.9 \%)$ that reply was among the 1,483 organizations and 232,588 people submitted surveys. An outline of this information is as being shown in Table 2. [16]

\subsection{Composition of researchers in each field}

The composition of researchers in each research fields from 1993 to 2003 is shown in Fig. 3. Generally speaking, the biggest difference of the composition is not seen through the whole term, but there is a little increase in the multidisciplinary domain field, and a little decrease is found in the fields of literature and medicine. The complete number of researchers was 
Table 2 Number of subjects and replies for 2001 survey.

\begin{tabular}{lrrrr}
\hline \multirow{2}{*}{ Research Institutions } & \multicolumn{2}{c}{ No. of subjects } & \multicolumn{2}{c}{$\begin{array}{c}\text { No. of replies } \\
\text { (response rate) }\end{array}$} \\
\cline { 2 - 6 } & Institutions & Individual & Institutions & Individual \\
\hline University & 671 & 208,662 & 668 & 139,078 \\
\hline Junior college & 551 & 15,849 & 519 & 12,887 \\
\hline Technical college & 62 & 4,449 & 62 & 4142 \\
\hline $\begin{array}{l}\text { Inter-university research } \\
\text { institute etc. }\end{array}$ & 20 & 1,805 & 21 & 1,097 \\
\hline $\begin{array}{l}\text { Ministry of Education, } \\
\text { jurisdiction organization } \\
\text { etc. }\end{array}$ & 18 & 556 & 13 & 379 \\
\hline $\begin{array}{l}\text { Private sector scientific } \\
\text { research organization }\end{array}$ & 161 & 1,267 & 83 & 815 \\
\hline Total & 1,483 & 232,588 & $1,366(92.1 \%)$ & 158,516 (68.2\%) \\
\hline
\end{tabular}

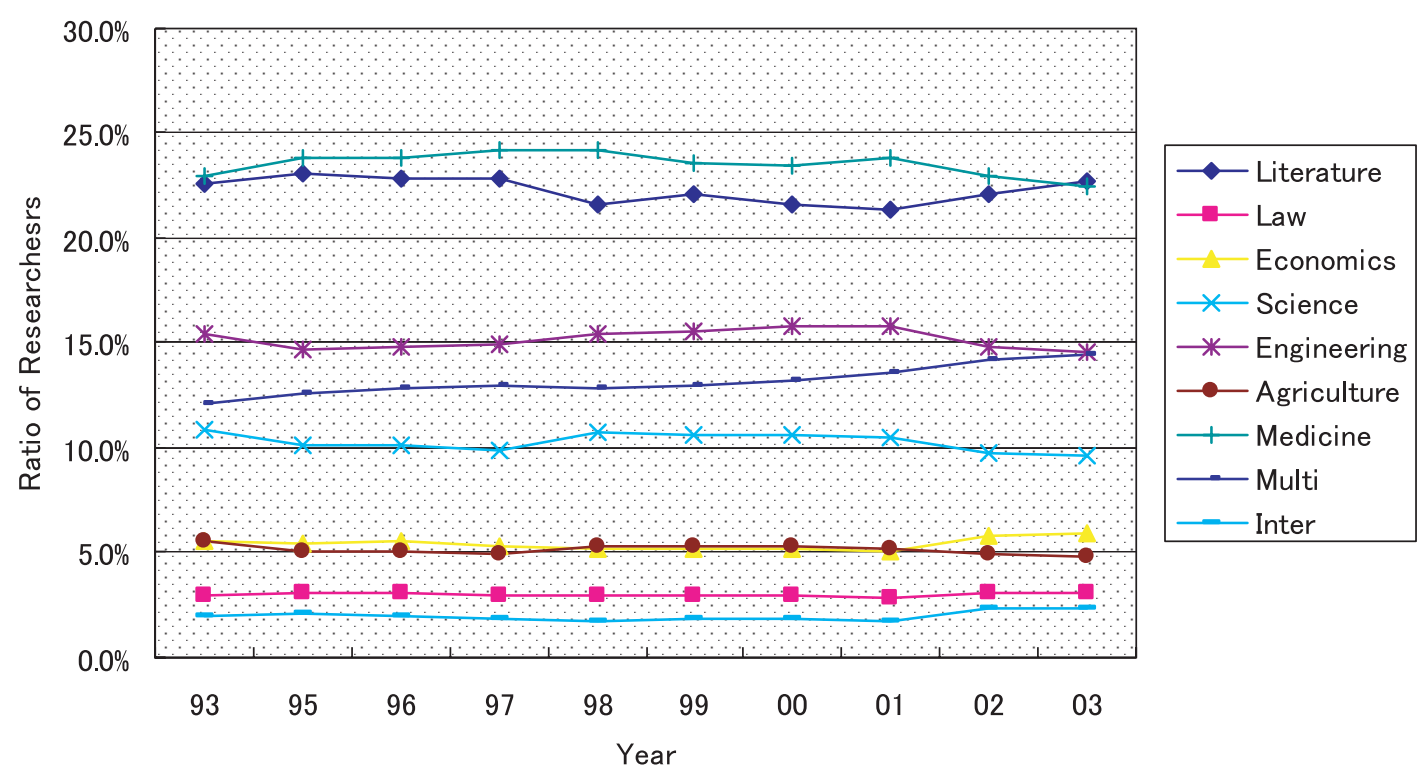

Fig. 3 Ratio of researchers in each research field.

slowly increased, so the number of researchers slightly increased in every field.

Using "Data in 2001", specifications on researchers in the multidisciplinary domain were carried out. As a result, basic biology researchers, including molecular biology among others, occupied $13.5 \%$, and those of information science, such as computer science and intelligence informatics, occupied $17.8 \%$ in the multidisciplinary domain field. These topics are related to life sciences, information, and telecommunications, which are selected as the important fields by the Science and Technology Basic Plan in 2001 and a highly expected area (A breakdown of the fields is shown in the appendix).

\subsection{Age of researchers in each field}

The average age of the researchers in each research field from 1993 to 2003 is shown in Fig. 4. In 1993 the average age of researchers in all fields was 46.5 and retained the same level till 1997. After 1997, the average age was lower till 2000. From 2001 the average age rose past the 1997 level. Researchers in the fields of economics and literature were in the eldest group and researchers in medicine were the youngest. The cause for this tendency was estimated that postgraduate students in doctorial courses, among others joined the total number of researchers. 


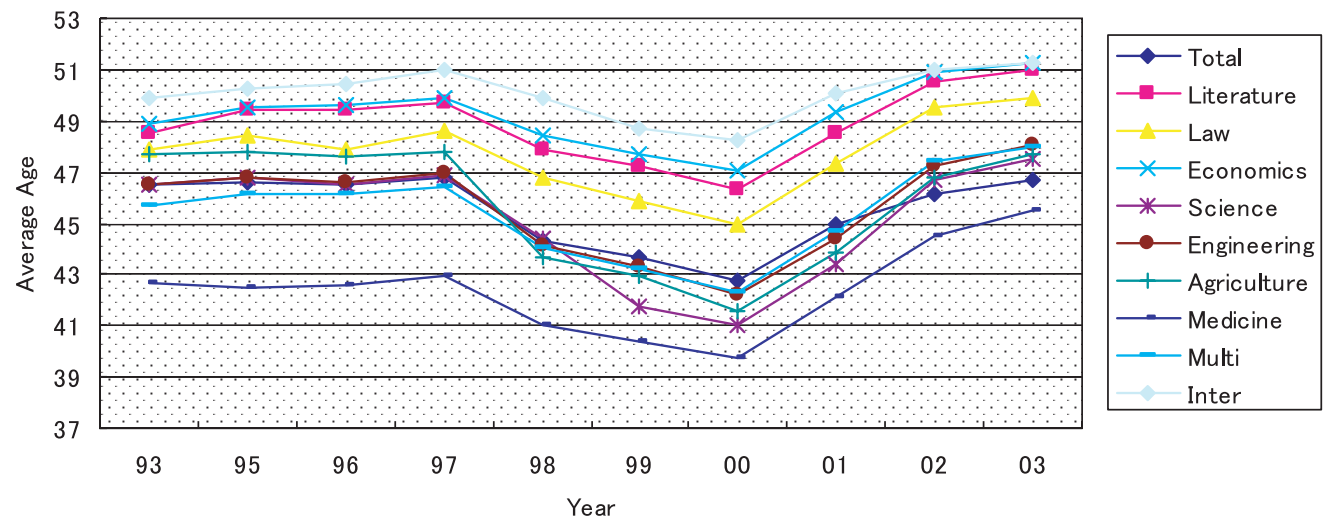

Fig. 4 Average age of researchers in each research field.

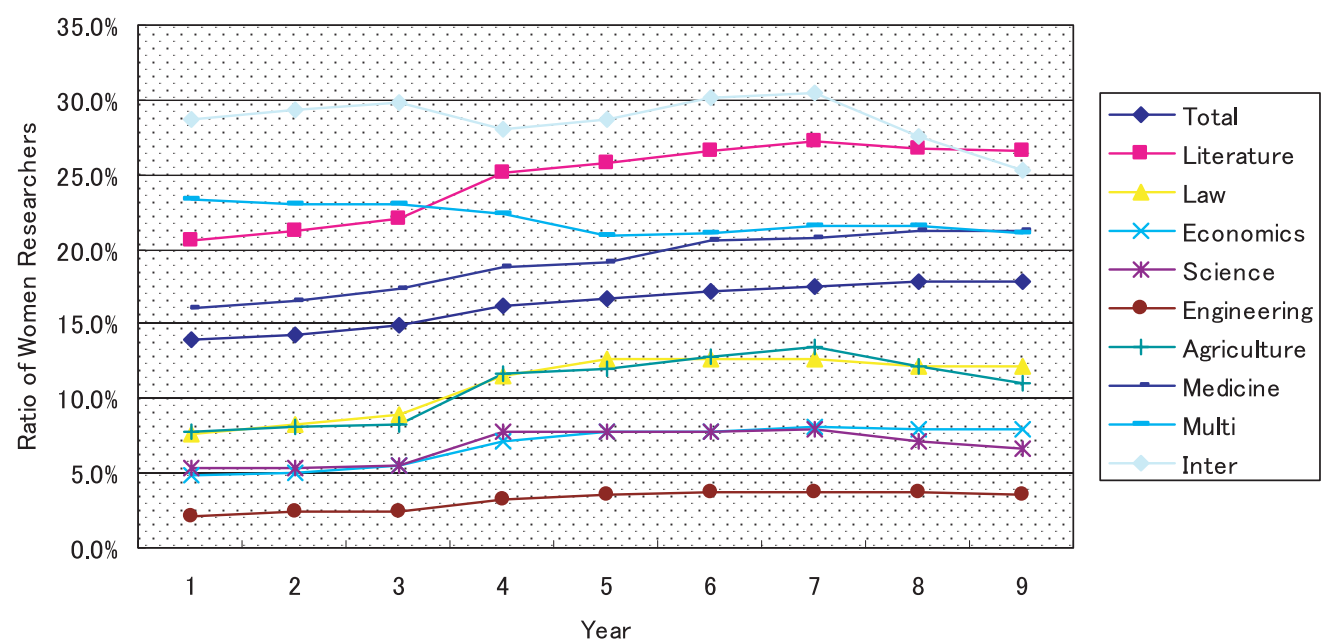

Fig. 5 Ratio of women researchers in each research field.

\subsection{Women researchers}

Expanding the opportunity for women researchers as one of the major strategies for improving the researcher population was proposed in policy published in 1992.

From the 1995 survey, detailed information on women researchers was reported. To compare manwoman ratios from 1995 to 2003, it is clear that the percentage of women researchers increased throughout the research population (1996: 14.0\%; 2003: 17.5\%). The ratio of women researchers in each research field is shown in Fig. 5.

However, large gaps still existed in the research fields. Literature was the field occupied by the highest number of women. Engineering was pointed out as the field with the fewest number of women. Even in 2001, only $3.7 \%$ of the researcher population in the engineering field was women. It was a markedly low percentage when compared with other research fields.

\subsection{Researchers with foreign names}

To improve the level of Japanese research activities, it was necessary for research institutes to open their door to foreign researchers and students. Items of the NII survey did not include individual nationality. Here "foreign researcher" means a researcher who does not have a Japanese style name (Henceforth called "researchers with foreign names").

The average age of researchers with foreign names in each research field from 1996 to 2003 is shown in Fig. 6. In 1996 and 1997, the rate of researchers with foreign names in all fields was about $1.5 \%$. As the categories of researchers expanded to part-timeservice researchers and postgraduate students in doctorial courses in 1998, the rate of researchers with foreign names increased. After that year, the average age was gradually shifted to the present level. The reason for this phenomenon is attributed to the fact that some researchers stayed for only a short time in Japan. It was difficult to accurately gather information on researchers 


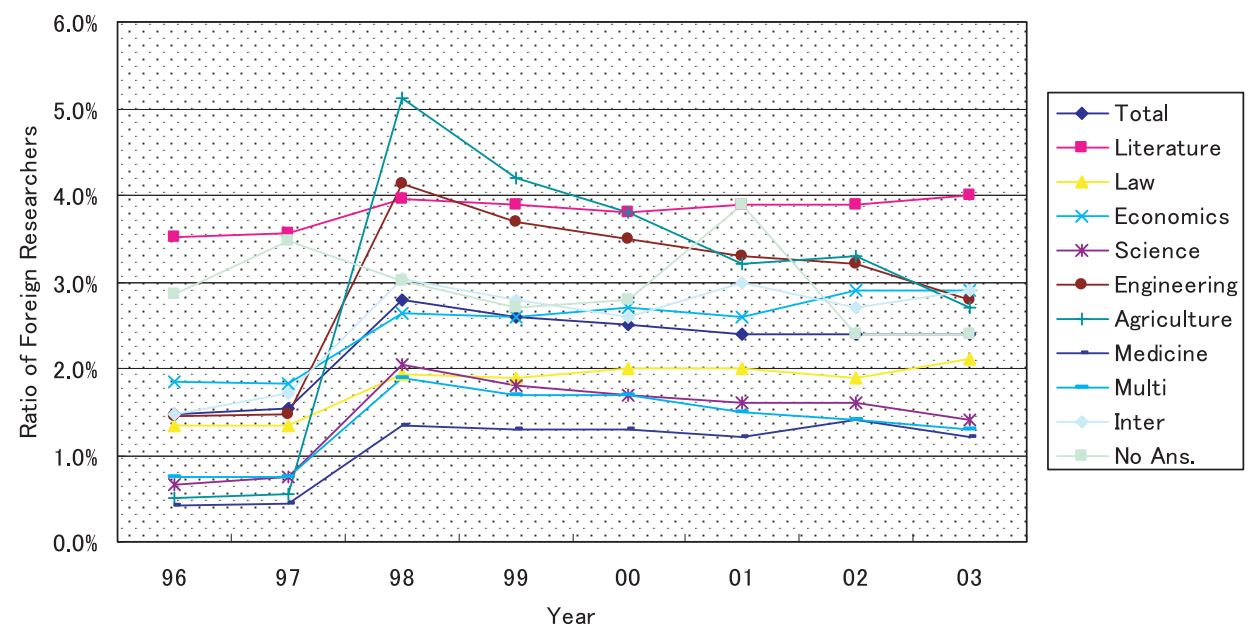

Fig. 6 Ratio of researchers with foreign names in each research field.

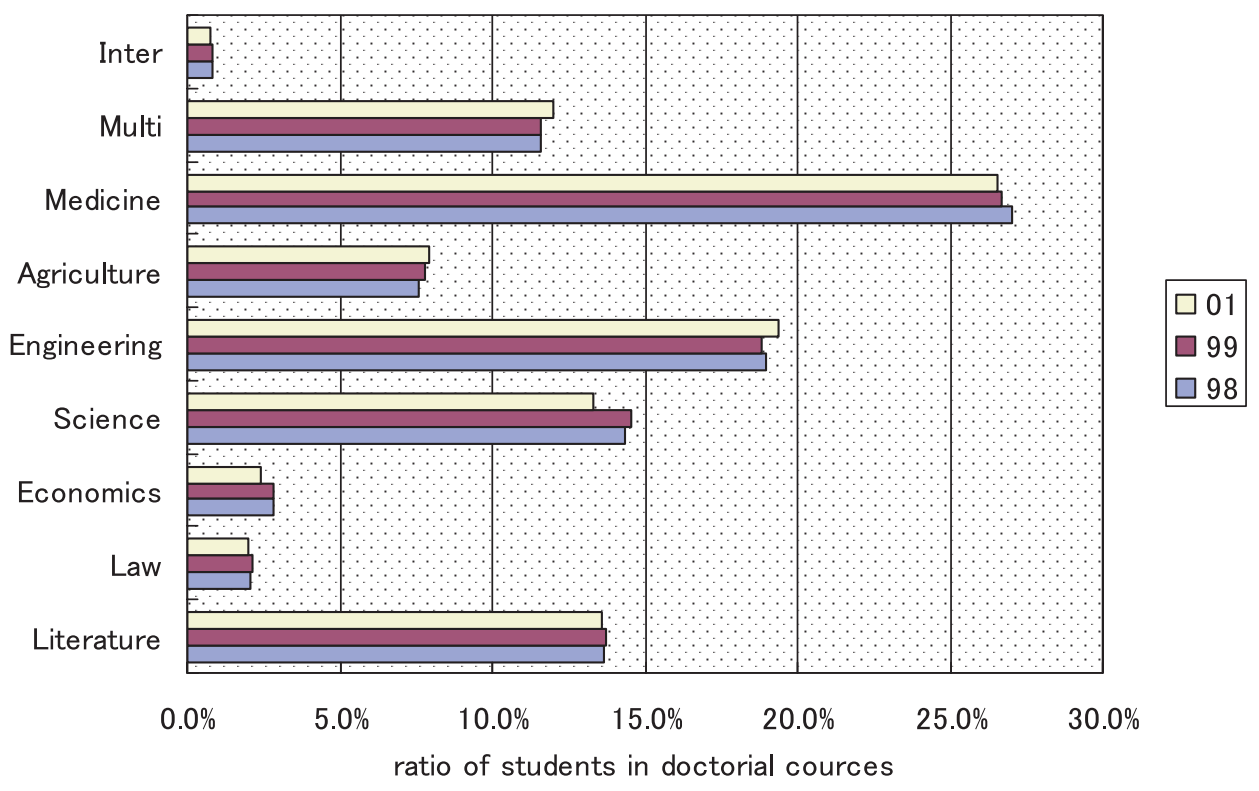

Fig. 7 Ratio of students in doctorial courses in each research field.

from abroad.

A major portion of the researchers belong to the fields of literature, engineering, and agriculture and almost of all of them were research associates or postgraduate students in doctorial courses. The internationalization of researchers was not enough yet.

\subsection{Students in doctorial courses}

Analyzing the research activities of the student (henceforth called "PhD. students") who are on register in the doctorial course of graduate schools which were added to the subjects for survey from 1998, could be effective in examining the improvement of graduate schools that train and cultivate younger researchers, which were included in policy made by the academic council in 1992.

There were 22,128 PhD. students in the 2001 survey, and those who belonged to a university were 22,126 (16,981 in national universities, 780 in public colleges, and 4,355 in private universities). Their research areas in 1998, 1999, and 2001 are shown in Fig. 7.

On then whole, the proportion of $\mathrm{PhD}$. students' research field has not remarkably changed from 1998 to 2001. According to Fig. 7, most PhD. students belong to the fields of medicine, engineering, science, and literature.

The composition of researchers and $\mathrm{PhD}$. students in each research field is shown in Fig. 8. 


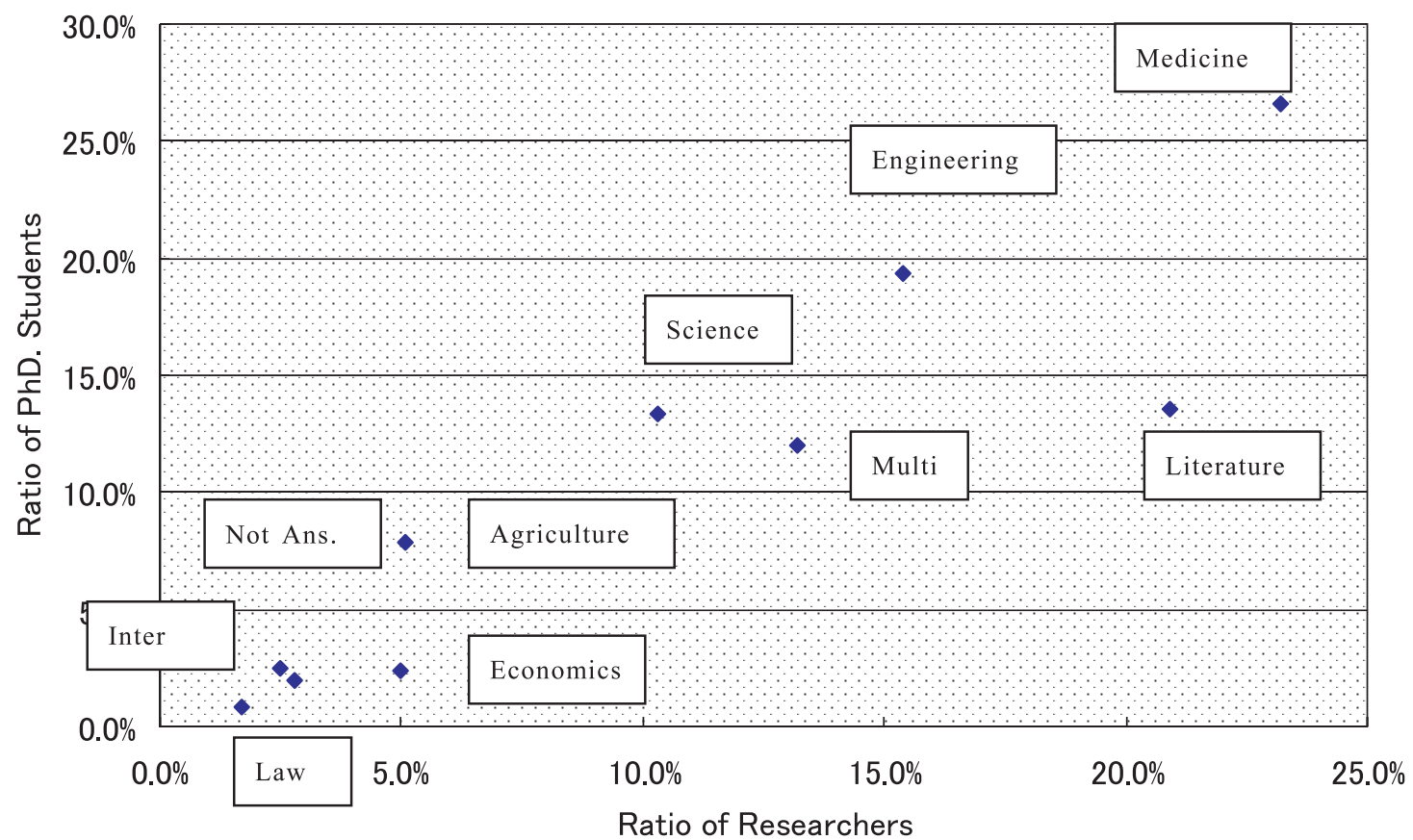

Fig. 8 Relation of researchers and PhD. students in each research field.

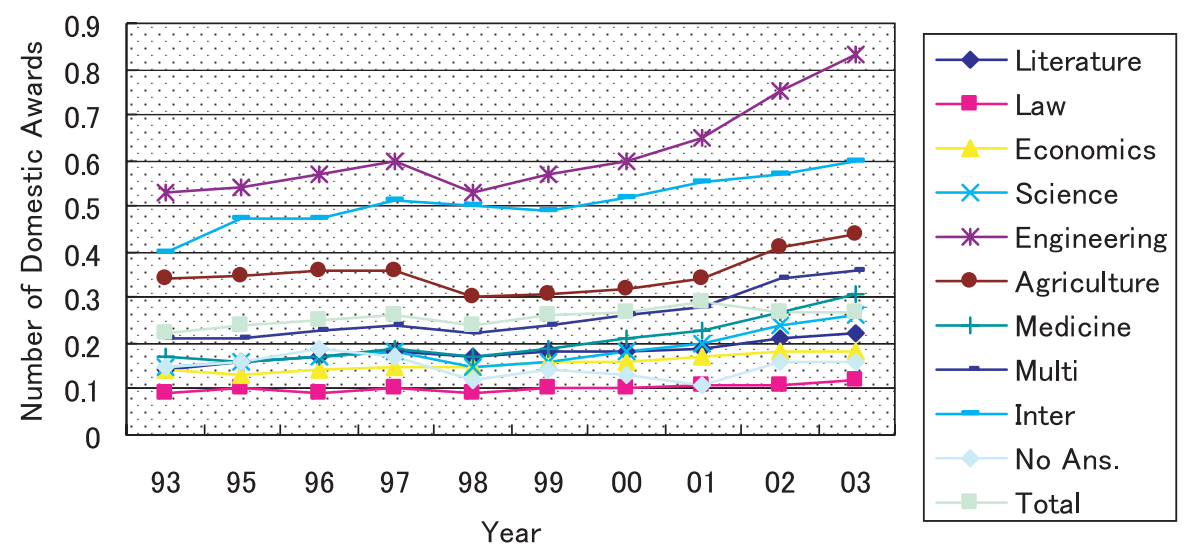

Fig. 9 No. of domestic awards per a person in each research field.

It is the rate in the fields of literature, multidisciplinary, and economics that are as low for the students as those compared to the researchers. However, the fields of medicine, engineering and science have high student-researcher ratios. The necessity for improvement in the humanities and social science areas were emphasized in 1992 and the situation outlines that there seldom are $\mathrm{PhD}$. degree acquired in these areas. This could affect younger researchers' motivation.

\section{Outputs of research}

\subsection{Awards}

Awards could be a sort of indicator that shows how research activities were evaluated. It would be meaningful to examine about the tendency of awards that researchers received.

Based on the survey from 1993 to 2001, trends on the average number of awards per researcher in each field and an award experience rate will be shown in Fig. 9-12. Here, a "domestic award" means an award presented by an organization inside Japan, and an "international award" means an award presented by an organization outside Japan.

We investigated databases from 1993 to 2003. They revealed that in resent years, researchers in the fields of engineering and the interdisciplinary domain re- 


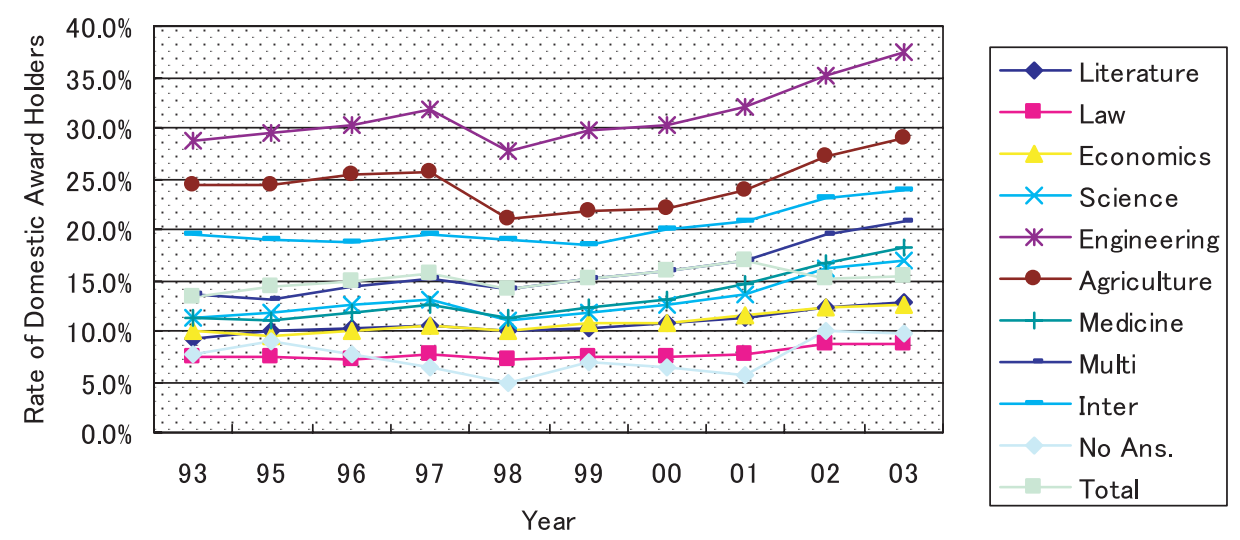

Fig. 10 Rate of domestic award holders in each research field.

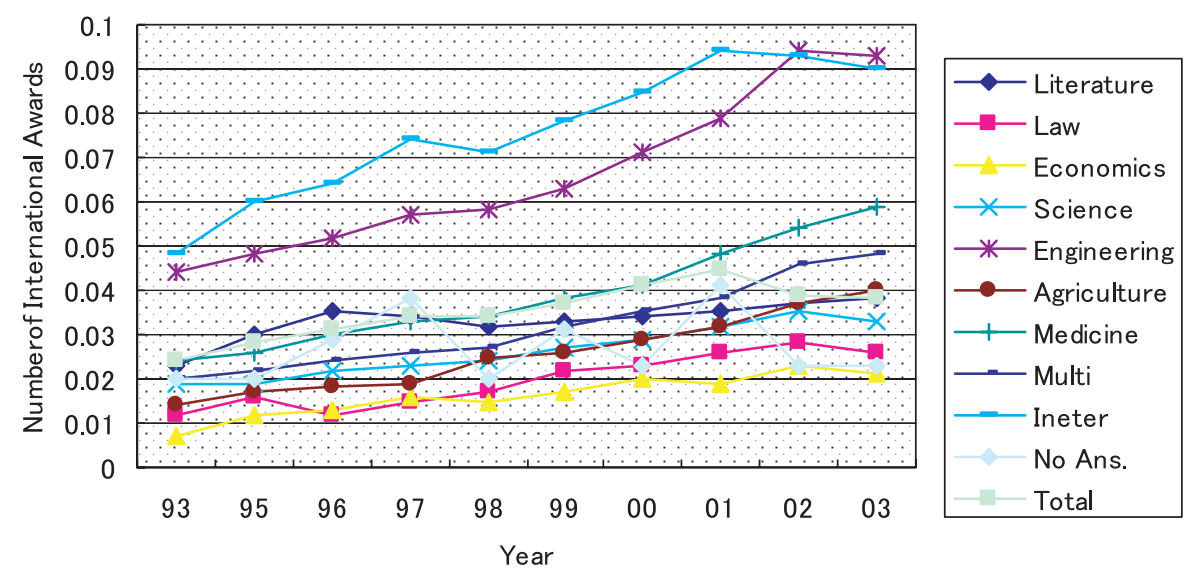

Fig. 11 No. of international awards per person in each research field.

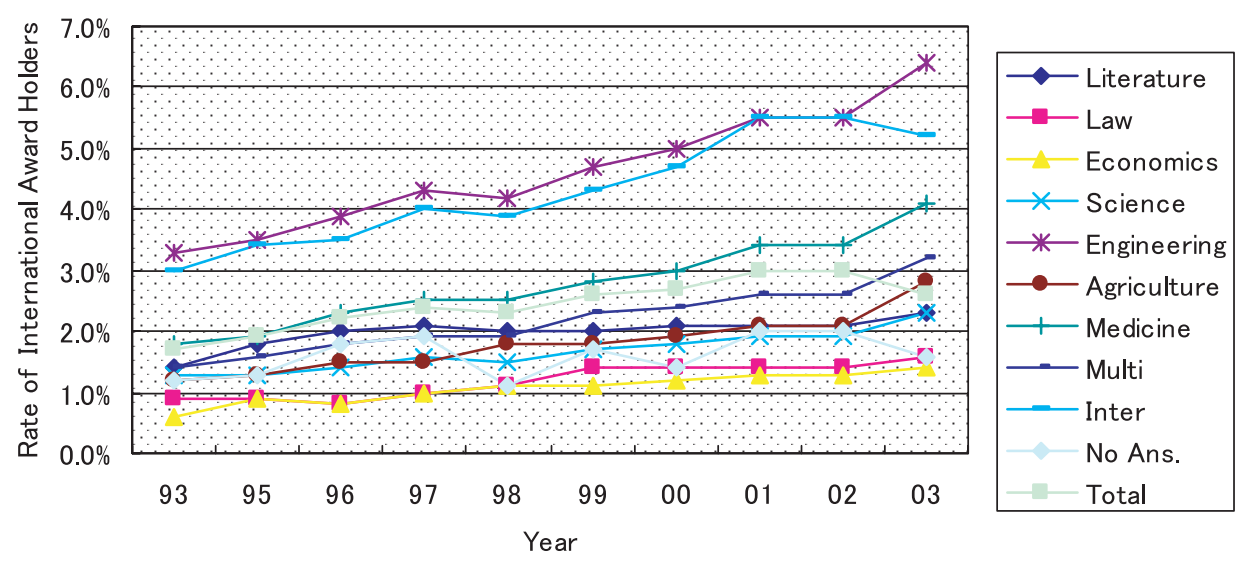

Fig. 12 Rate of international award holders in each research field.

ceived more domestic awards than any other fields. Researchers in the fields of interdisciplinary and science received more international awards than researchers in other fields.

First, the number of domestic awards shows that engineering and the interdisciplinary domain maintained over 0.4 awards per a researchers throughout the years. Other fields, including agriculture, the multidisciplinary domain, and medicine have some differences from these fields. The numbers of awards remains on 
the same level.

Secondly, the number of international awards shows that the interdisciplinary domain and science fields maintained high positions throughout the years in comparison with medicine and humanities. The numbers of awards have been gradually rising.

Thirdly, the engineering and science fields have reversed positions in the domestic and international awards, and the law and economics fields have lower positions both in the domestic and international awards.

The average number of awards and the average rate of award holders increased for both the domestic and international awards. However, the number of awards in a questionnaire is the accumulation from past to present. Therefore, the number of awards of the newest investigation report is estimated to increases more than in the past investigation reports.

The growth in the number of awards and the people receiving an award in the engineering field is very clear both domestically and internationally. In particular, researchers whose study subjects are electric \& electronics engineering, architecture, and material reported many awards. Agriculture, medicine, and the interdisciplinary domain are mentioned as fields whose awards are especially from foreign organizations.

Although the interdisciplinary domain also has many awards from outside the country, it cannot identically correlate to other fields, because the types of awards and the number of researchers in this field differ in many ways. Most awards reported by researchers in this field are relevant to design and public advertisement or campaign. It may be difficult to define which award is appropriate for recognition as an effort for their research activities. This matter is also applicable to other research area. Furthermore, the number of researchers in the interdisciplinary domain is extremely small so it is hard to compare them to other research areas using statistical methods.

Alone with the interdisciplinary domain, researchers in the field of literature also reply to considerable awards in the survey. In this research area, $36 \%$ of the awards were obtained by researchers who study aesthetics (including fine arts). Researchers who study aesthetics receive higher of numbers of awards, but their awards, such as letters of thanks from local organizations, final year projects in their courses and prizes from their own institutions, were hardly recognized as objective evaluation criteria for their academic research activities.

It should be noted that according to the "Data in 2001" one third of researchers in literature engage in psychology, sociology, education, and social anthropology, but the numbers of awards that were obtained by these researchers is relatively smaller than in other lit- erary subjects. As mentioned before, the promotion of these areas was proposed in the 1992 policy, but the situation is still stagnant. The common component in these areas is the use of statistical or subjective research methods, so weakness in research methodologies should be considered as a cause of the stagnant of these areas.

\subsection{Research institutions with many awards and num- bers of award holders}

Research institutions with many awards and numbers of awards holders are shown in Table 3, compiled from the "Data in 2001".

It is obvious that national universities, especially major national universities, are located in the higher rankings of awards and award holders. According to the report, which is based on the survey from 1993 and 2003, the $\mathrm{PhD}$. holder rate is higher in national universities. Even postgraduate students were counted as subjects for survey in 1998; more than half of the researchers in national universities hold PhDs. This tendency would indicate a higher evaluation for national universities, especially major national universities. However, those universities have well-supported foundation for research throughout their histories and a situation for obtaining societal respect has been arranged.

\subsection{Research papers}

The most important measure for research activities is the number of research papers. Fig. 13-1 thru 13-3 show the number of research papers in ISI citation index databases (presented by Thomson Corporation of U.S.) from 1981 to 1997. Fig. 13-1 indicates the number of papers in the fields of humanities and social science, likewise Figs. 13-2 and 13-3 indicate those in the fields of science and engineering and in biology and medicine, respectively. The university of Tokyo and other major national universities occupied top positions in productive research institutes. [13]

So as to explain this tendency, the relation between number of research papers and number of researchers is analyzed using three scattergrams. Fig. 14-1 thru 14-3 show the relations between them in fields of humanities \& social sciences, science \& engineering, and biology $\&$ medicine, respectively. In the Figs. 14-2 and 14-3 the number of research papers is well proportional to the number of researchers. However, in Fig. 14-1 the number of research papers is only slightly proportional to the number of researchers. Generally speaking, humanities and social sciences are different from natural sciences inform the viewpoint of human power. The reason for the difference is attributed to the dependence on individual ability or organizational potentiality in each 
Table 3 Research institutions with many awards and award holders.

\begin{tabular}{rlr|rlr}
\hline & Institution name & $\begin{array}{c}\text { No. of } \\
\text { awards }\end{array}$ & \multicolumn{2}{c}{ Institution name } & \multicolumn{2}{c}{$\begin{array}{c}\text { No. of award } \\
\text { holders }\end{array}$} \\
\hline 1 & Tohoku University & 2019 & 1 & Kyoto University & 1050 \\
2 & Kyoto University & 1989 & 2 & University of Tokyo & 1010 \\
3 & University of Tokyo & 1961 & 3 & Tohoku University & 927 \\
4 & Osaka University & 1894 & 4 & Osaka University & 906 \\
5 & Tokyo Institute of Technology & 1499 & 5 & Hokkaido University & 663 \\
6 & Hokkaido University & 1126 & 6 & Kyushu University & 627 \\
7 & Kyushu University & 1071 & 7 & Tokyo Institute of Technology & 597 \\
8 & Nagoya University & 1061 & 8 & Nagoya University & 546 \\
9 & Nihon University & 852 & 9 & University of Tsukuba & 485 \\
10 & University of Tsukuba & 807 & 10 & Nihon University & 469 \\
11 & Okayama University & 655 & 11 & Okayama University & 391 \\
12 & Hiroshima University & 636 & 12 & Hiroshima University & 386 \\
13 & Chiba University & 509 & 13 & Chiba University & 280 \\
14 & Kumamoto University & 500 & 14 & Niigata University & 260 \\
15 & Niigata University & 414 & 15 & Kumamoto University & 239 \\
\hline
\end{tabular}

Note: no mark = National universities, \# = Public universities, $+=$ Private universities.

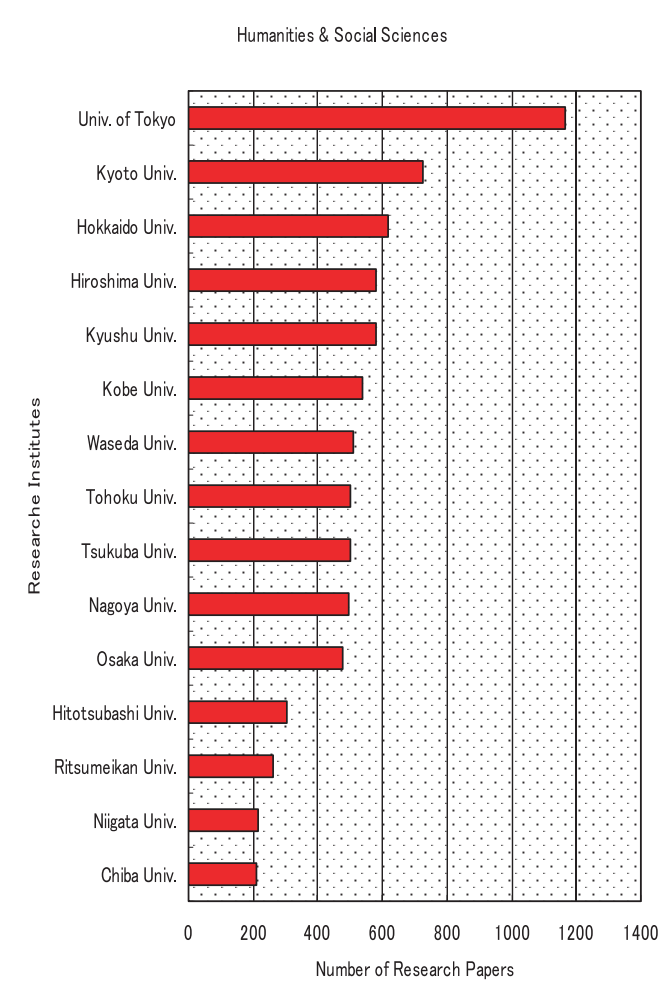

Fig. 13-1 No. of humanities and social sciences research papers*.

research field.

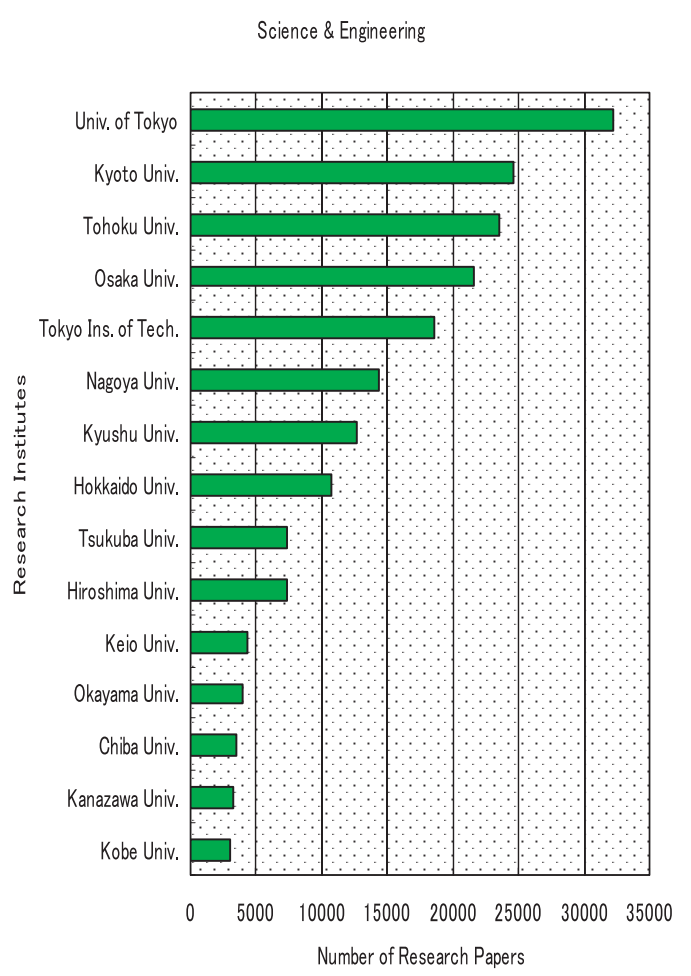

Fig. 13-2 No. of science and engineering research papers*.

\subsection{Patents}

As other measures for examining how academic research activity is recognized in society, we analyzed patents that are obtained by researchers. It should be 
Table 4 Research institution with many reported patents and patent holders.

\begin{tabular}{rlr|rlr}
\hline & Institution Name & $\begin{array}{c}\text { No. of } \\
\text { patents }\end{array}$ & \multicolumn{2}{c}{ Institution Name } & \multicolumn{2}{c}{$\begin{array}{l}\text { No. of patent } \\
\text { holders }\end{array}$} \\
\hline 1 & Tohoku University & 810 & 1 & Tohoku University & 127 \\
2 & Tokyo Institute of Technology & 544 & 2 & Osaka University & 91 \\
3 & Kyushu University & 416 & 3 & Tokyo Institute of Technology & 80 \\
4 & Osaka University & 357 & 4 & Kyushu University & 74 \\
5 & Fukui University of Technology & 316 & 5 & University of Tokyo & 69 \\
6 & University of Tokyo & 247 & 6 & Hiroshima University & 53 \\
7 & Kyoto University & 224 & 7 & Kyoto University & 52 \\
8 & Saitama University & 219 & 8 & Hokkaido University & 43 \\
9 & Kanazawa Institute of Technology \\
10 & Kagoshima University & 178 & 9 & Nihon University & 40 \\
\hline
\end{tabular}

Note: No mark = National universities, \# = Public universities, += Private universities.

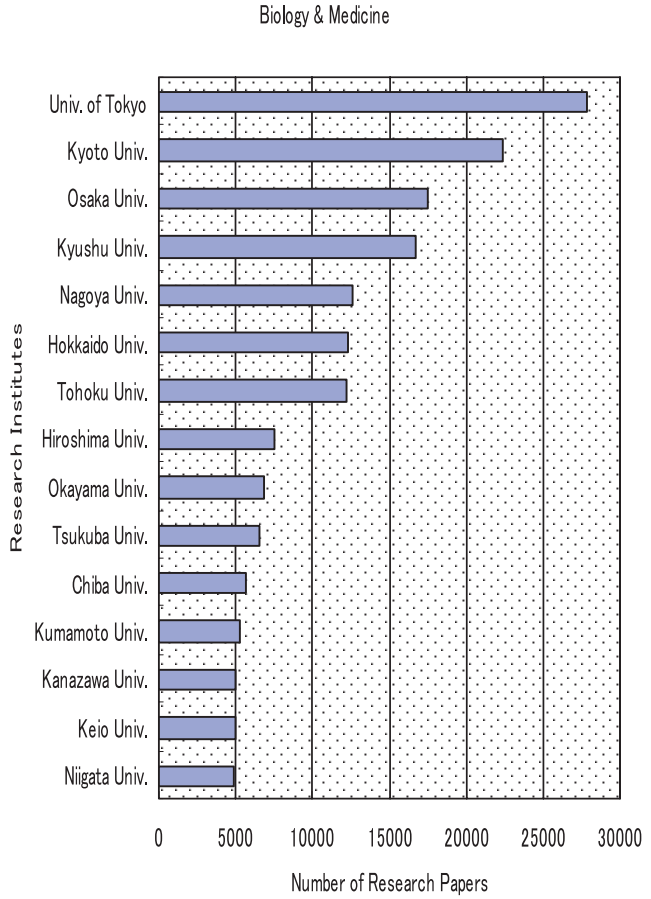

Fig. 13-3 No. of biology and medicine research papers*.

(* Negishi et al., 2000)

noted that researchers who had the opportunity to obtain a patent were limited in particular areas, so this analysis could apply to only those areas related to industry.

According to the "Data in 2001", 11,463 patents were reported by 2,323 researchers. More than $65 \%$ of the reported patents were obtained by researchers in the engineering field. Among those researchers who study engineering and report their patents, more than $30 \%$ of them engage in electrical \& electronics engineering.
Concentrations of awards and patents in that research subject have been confirmed. In addition, some engineering researchers who report patents carry out their study with medical equipment makers.

The numbers of researchers who reported patent and the numbers of patents obtained by them in each research institution are shown in Table 4.

As also shown in Table 4, the number of researchers who reported their patents and the number of patent researchers in each research institution that reported are high for the national universities, especially the six institutions that are presented in bold text that are high in both numbers of patent-reported researchers and numbers of reported patents. There were 6,259 patents, approximately $55 \%$ of all the reported patents, which were obtained by the researchers who belong to national universities. In patent permission, as well as award acquisition, the national universities are in a dominant position. Moreover, the tendency, pointed out before, of older national universities receiving high evaluations could be seen from the situation of patent permission.

\section{Consideration of research activities}

As previously mentioned, no significant change was seen in the researchers during this decade, but the environment in which the research activities were carried out has been modified by the Japanese cabinet. The Japanese government set out the "Science and Technology Basic Law" in 1995, then declared "The Science and Technology Basic Plan (for 2001-2005)" with actual procedure to promote academic research activities in March 2001. This plan basically aimed at establishing a country based on science and technology creativity. As strategies for the aim, four areas: (1) life sciences; (2) information technology; (3) environmental science; and (4) nanotechnology and materials, 
Humanities \& Social Sciences

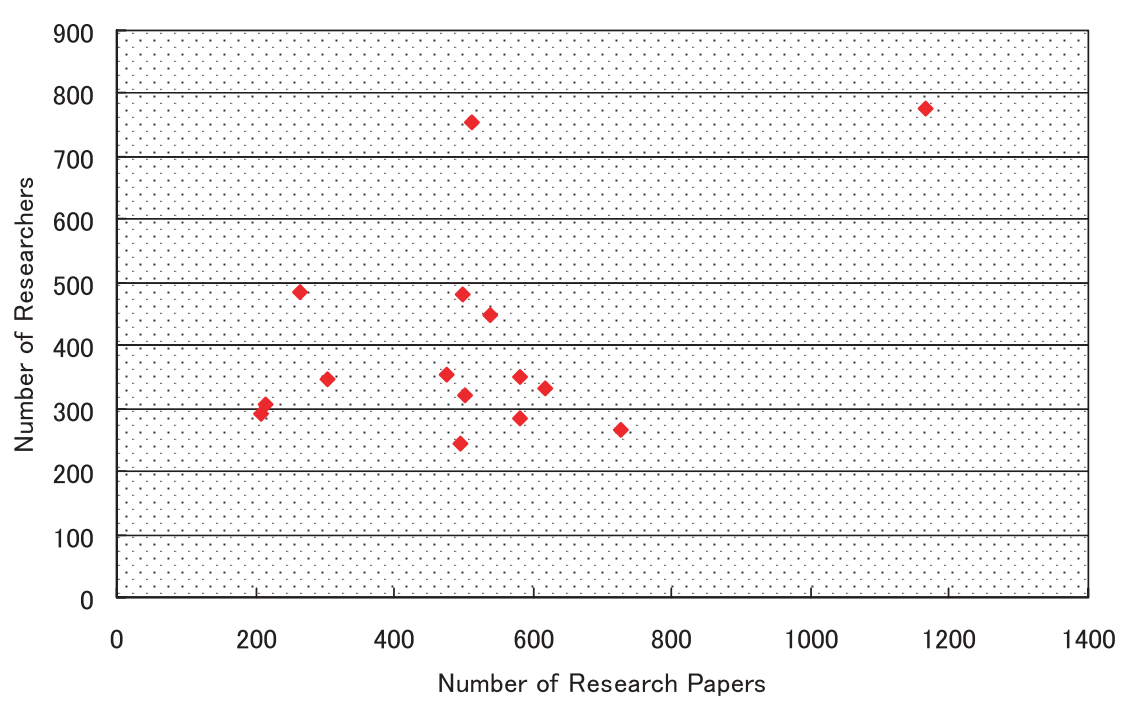

Fig. 14-1 Research papers vs. researchers in humanities and social sciences*.

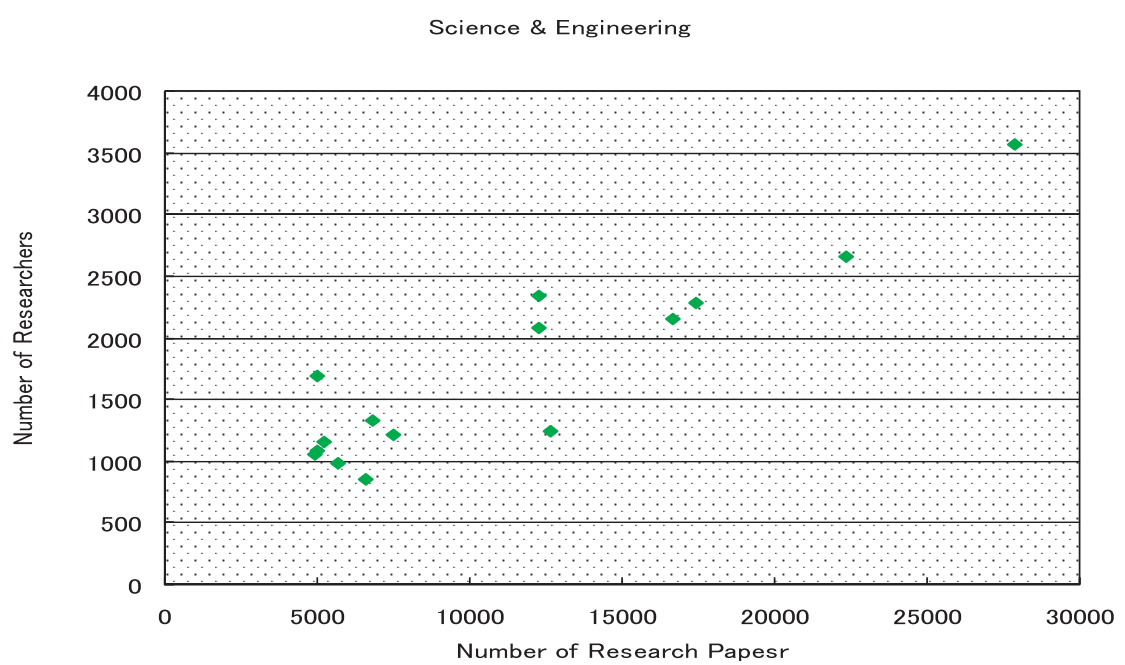

Fig. 14-2 Research papers vs. researchers in science and engineering".

were prioritized, and facilitate cooperation among the academic institutions, the government and public sector, and industrial companies. One of the easily recognizable changes could be the organizational change of national universities to public corporations from April 2004.

Although the Japanese government have been carried out the policy for the promotion of research activities since the early 90's, the Council of Science and Technology policy (CST), attached to the Japanese Cabinet, was opinionated before starting the 3rd term of the plan. According to the council, Japanese researchers' performance would not obtain appropriate evaluation interna- tionally in proportion to a sum of money for research activities?

They reported that Japan had the largest number of researcher per 10,000 peoples and the financial supply for the research activities per GDP was the highest among five countries (USA, UK, Germany, and France). However, the frequency order of Japanese academic papers cited by other researchers was not very high during the year of 1991 to 2001. Instead Japan retarded, Germany, France, Canada, Italy, and Austria, have advanced to a higher ranking. [14] The council emphasized that compare with the money that was spent by researchers and research institutions, their pro- 
Biology \& Medicine

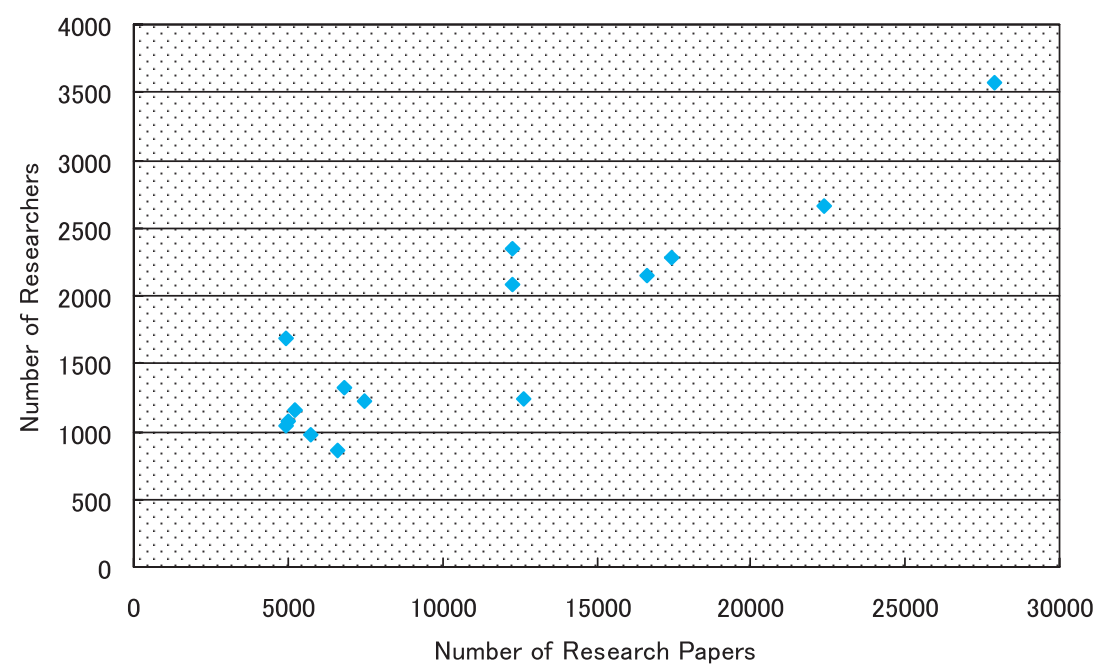

Fig. 14-3 Research papers vs. researchers in fields of biology and medicine*.

( ${ }^{*}$ No. of research papers from Negishi et al., 2000)

ductivities and evaluation from outside of Japan would not be enough, so that the solutions for those points should be considered before the start of the 3rd term of the plan.

This report will attempt to examine some factors that are associated with the improvement of research quality and research forms with compared to other countries, especially EFTA ${ }^{1)}$ countries.

At First, it is obvious that a Japanese researcher experienced fewer international joint research than that those in Europe and for a long time this has been pointed out by the CST with the necessity to modify it. The data consisted of researchers who belonged to Japanese academic institutions in 2001 and showed only small opportunities to take part in international research co-operation in each research field.

The components for research programs in each research field in 2001 are shown in Fig. 15. The classifications of research programs includes "Personal Research", "Joint Research Within Institute/campus", "Domestic Joint Research", "International Joint Research," and "Not Clear". "Personal Research" is a major style in the field of humanities and social sciences. Science is the highest rated of field for international joint research. Its rate is $10.9 \%$. Medicine has the highest rate for joint research. It has a rate of $43.9 \%$ for "Joint Research within Institute/Campus" and a 5.5\% rate for "International Joint Research". The range of all fields is $2.4 \%$ to $10.9 \%$, so the rate is low on the whole.

1) EFTA: European Free Trade Association includes Austria, Finland, Iceland, Liechtenstein, Norway, Sweden, and Switzerland.
Fig. 16 shows the number of international joint researches in each field. Engineering, literature, and the multidisciplinary domain have the highest numbers of the international researches, and the interdisciplinary domain, law, and economics have lowest. This tendency depends on the population of researchers in each field.

The CST also reported this circumstance, and then described the importance of international research cooperation. It can be seen that Japanese researchers had fewer experiences to write their papers under international collaborations. However, approximately $30 \%$ of European researchers wrote papers in collaboration with researchers in other countries (UK: 29.2\%, Germany: 32.9\%, France: 33.9\%. These are Science and Engineering indicators from the 1998, Science and Technology White Paper cited in 1999). Although, the percentages of Japanese researchers' experiences of international collaboration increased in 1998, it would still be less familiar than researchers in other countries.

As language produces disadvantages for Japanese researchers, this may be a possible explanation. Among academic research fields, English is the most largely spread language so major academic journals are usually written in English. Even though, there are some other procedures for overtaking language differences, such as setting out joint research or form research partnerships. Japanese researchers are more likely to carry out their research activities with other Japanese speakers.

It can be found in the data below (Table 5); when Japanese researchers cite academic papers, many of 


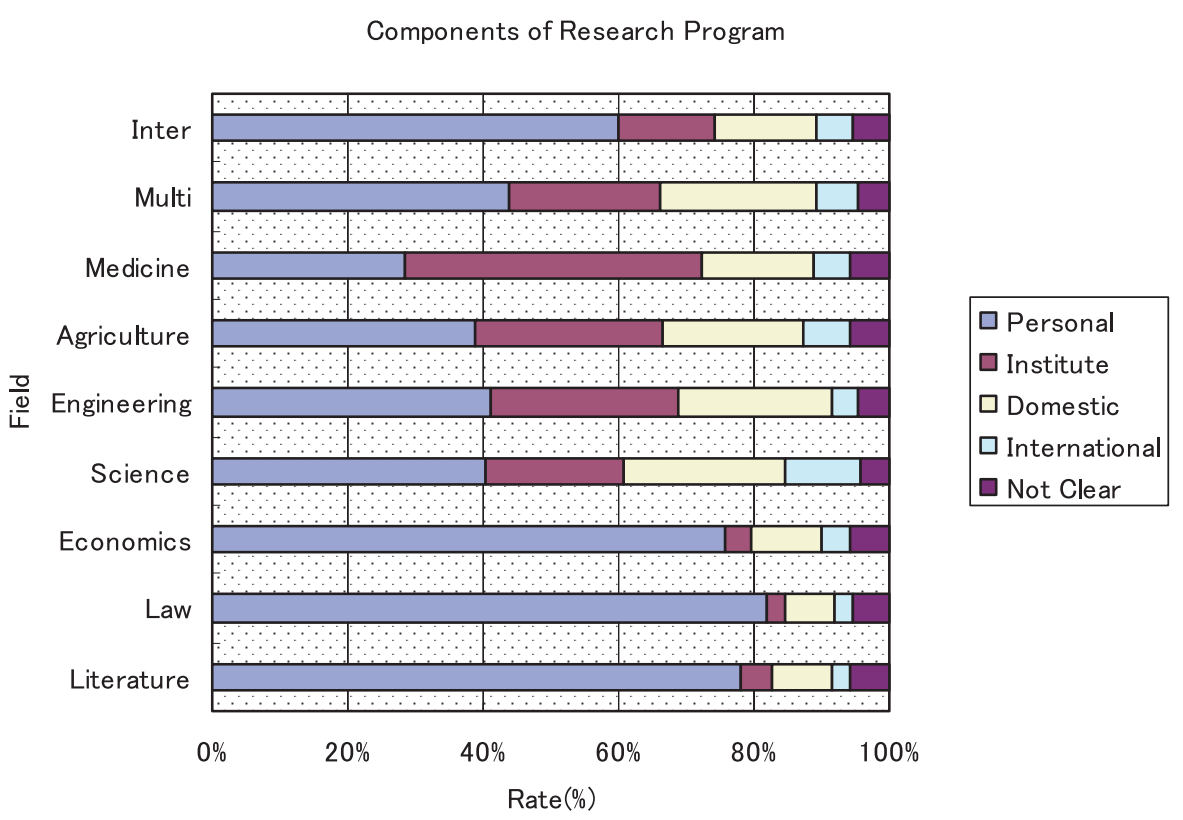

Fig. 15 Research programs research components in 2001.

International Joint Research Programs

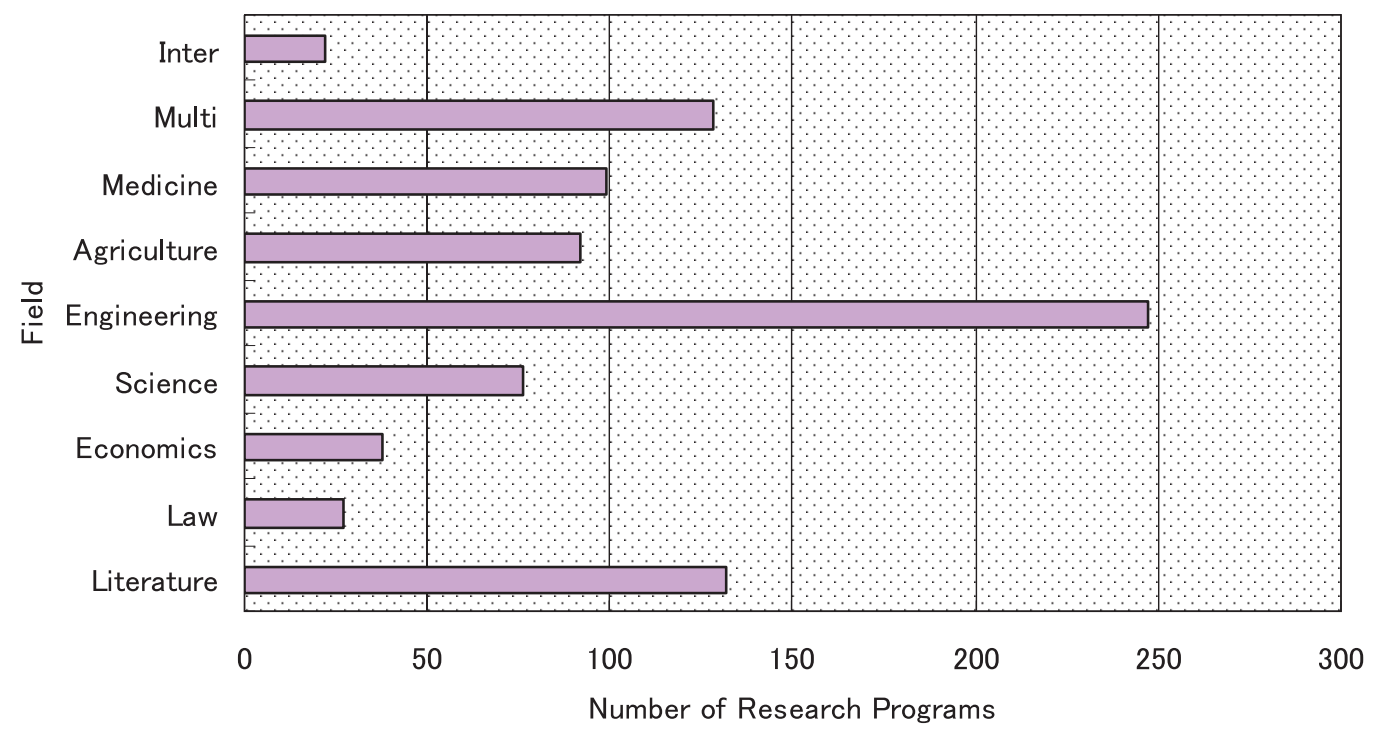

Fig. 16 No. of international joint research projects in 2001.

them cite papers written by American researchers and a balance of citations on academic papers written in other countries. Japanese academic scenes have large differences among the eight listed countries. It should be noted that because of the size differences in many points, the USA could be an exception in this argument, the frequency of citation on academic papers written in one's own country was quite high in Japan.
As previously mentioned, language could produce difficulties for Japanese researchers to join international researchers' networks; however, Japanese researchers would be in quite a homogeneous environment. This situation may not be appropriate to plan and set out their research activities with subjective views.

CST called this circumstance lower efficacy or lower productivity regardless of larger supplies. However, fi- 
Table 5 Percentages of research paper citations by researchers in each country.

\begin{tabular}{lccccc}
\hline & Own country USA & $\begin{array}{c}\text { European } \\
\text { Countries }\end{array}$ & Japan $\begin{array}{c}\text { Other } \\
\text { countries }\end{array}$ \\
\hline Japan & $37 \%$ & $35 \%$ & $19 \%$ & - & $9 \%$ \\
\hline USA & $67 \%$ & - & $21 \%$ & $4 \%$ & $8 \%$ \\
\hline UK & $30 \%$ & $37 \%$ & $\begin{array}{c}22 \% \\
\text { (except UK) }\end{array}$ & $4 \%$ & $7 \%$ \\
\hline Germany & $27 \%$ & $37 \%$ & $\begin{array}{c}23 \% \\
\text { (except GER) }\end{array}$ & $5 \%$ & $8 \%$ \\
\hline France & $24 \%$ & $38 \%$ & $\begin{array}{c}24 \% \\
\text { (except FRA) }\end{array}$ & $5 \%$ & $9 \%$ \\
\hline Korea & $12 \%$ & $44 \%$ & $12 \%$ & $22 \%$ & $10 \%$ \\
\hline China & $19 \%$ & $35 \%$ & $9 \%$ & $28 \%$ & $8.9 \%$ \\
\hline Taiwan & $19 \%$ & $41 \%$ & $8 \%$ & $22 \%$ & $10 \%$ \\
\hline & & $($ Science and Technology Agency, 1999$)$
\end{tabular}

nancial supply would not work independently to improve research quality, and other aspects should be considered. European countries spent less money on research activities, but they could keep closer networks among researchers, so they may have more alternatives when they carry out their research, such as international joint research, sharing facilities or publication of results in other languages.

It could be predicted from the data shown that the leading part of Japanese academic scene is dominated by relatively higher-aged researchers who have already obtained enough evaluation, instead of younger researchers who are available to engage in challenging research topics. At present, Japanese researchers may obtain moderate evaluation and keep a quality of their researches, however most of them experienced an "economic bubble" that are completely different from the present situation. Slight damage might occur to the Japanese academic scene in the near feature unless appropriate resolutions are planned and completed.

As for another advantage, the rates of students who go further with research programs in European areas were relatively higher than in other areas. Furthermore, students could have been encouraged to study in other EU countries to construct co-operations among those areas. Therefore, EU countries may keep a certain number of younger researchers and social approvals through Erasmus programs.

\subsection{Evaluation of research}

Yano and I extracted about 2000 researchers in field of informatics from the "Directory of Researchers" and sent them questionnaires on their research activities, one question of which was, "How do you measure the qualification of creative researches?" There were 397 answered questionnaires.

The researchers ranked twelve items from 0 to 10 points. The summation of each item is indicated in Fig. 17. [15]

The three highest-scoring items were, "Appeared in foreign refereed journals", "Appeared in domestic refereed journals", and "New technology development". The Three lowest-scoring items were "Presentation at domestic conferences", "Had many questions and comments from other researchers", and "Appeared in business journals".

"Awards from academic societies", "Patent application", and "Invited to lecture" have middle ranking positions.

The author estimated that Japanese researchers took the important view of research papers as the base of evaluation. In natural sciences, the English journal is the measure of evaluation, but Japanese journals remain a major tool of evaluation for researchers in the fields of humanities and social sciences.

\subsection{Conclusions}

\subsubsection{Joint research}

It is necessary to obtain well-balanced research populations that vary according to gender and generation. Then, to train and cultivate young researchers, the Science Council proposed to increase the opportunity for $\mathrm{PhD}$. students to work as research assistants, and support them financially. Furthermore, the Science Council suggested the possibility for accepting different types of organizations such as private sector companies, and/or public or governmental offices, to cooperate with research institutes by appropriate form. In other words, research institutes would be able to receive financial support from other organizations. Moreover, another plan was suggested for the formation of a new research organization to carry out world-wide research projects with experts. In this plan, the organization was called the Center of Excellence (COE), where researchers from various countries would work together to study highly specified research areas.

Fig. 18 shows the trend of domestic joint researches in each field.

The growth rate of domestic joint research appeared in the fields of science, agriculture, engineering, and other domains, except in the fields of law, literature and economics.

In Fig. 19, the rate of international joint research, as well as for domestic joint research, grew for the science and agricultural fields. However, in the fields of law, literature, and economics, the rate of the research did not grow. 


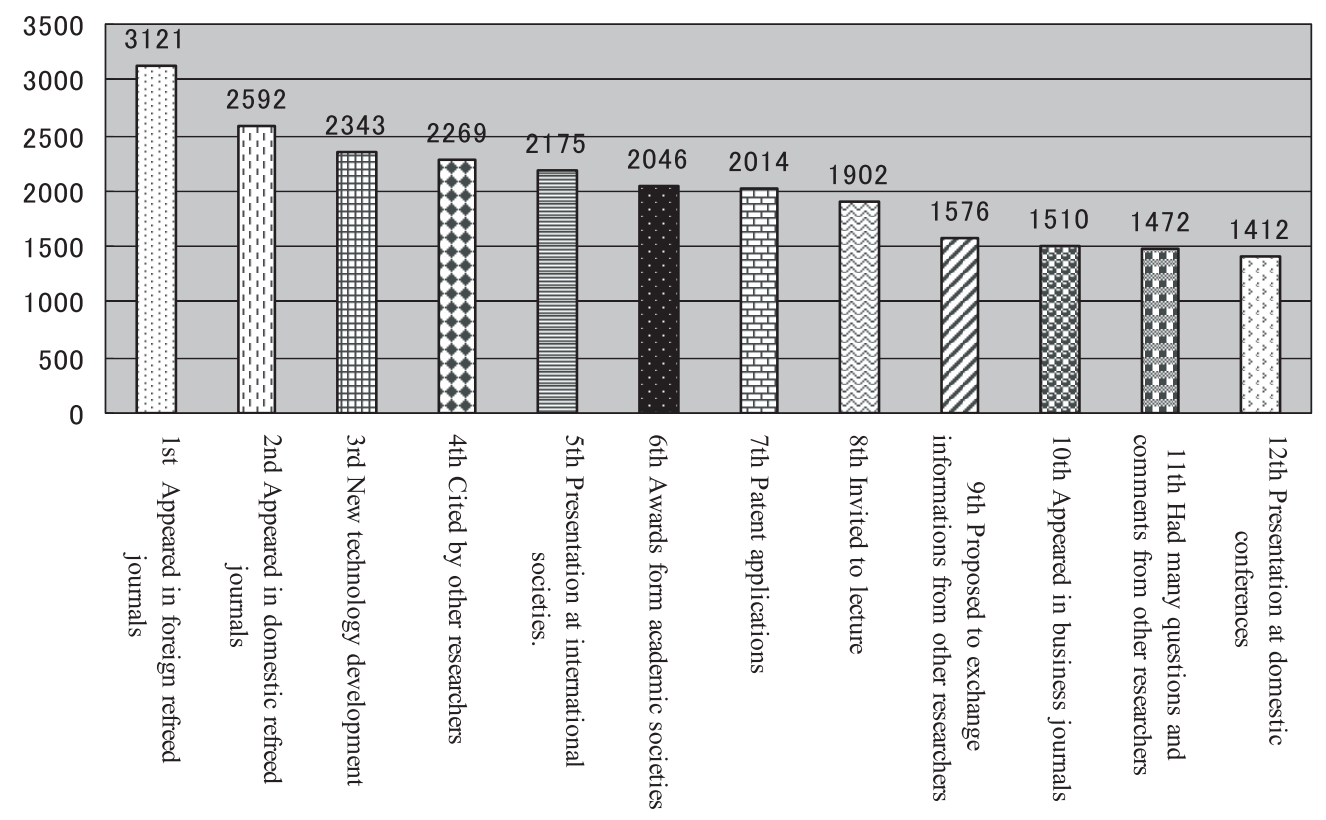

How do you measure the quality of res earch?

(Shibayama and Yano,2004)

Fig. 17 Measure of quality of research.

Domestic Joint Research

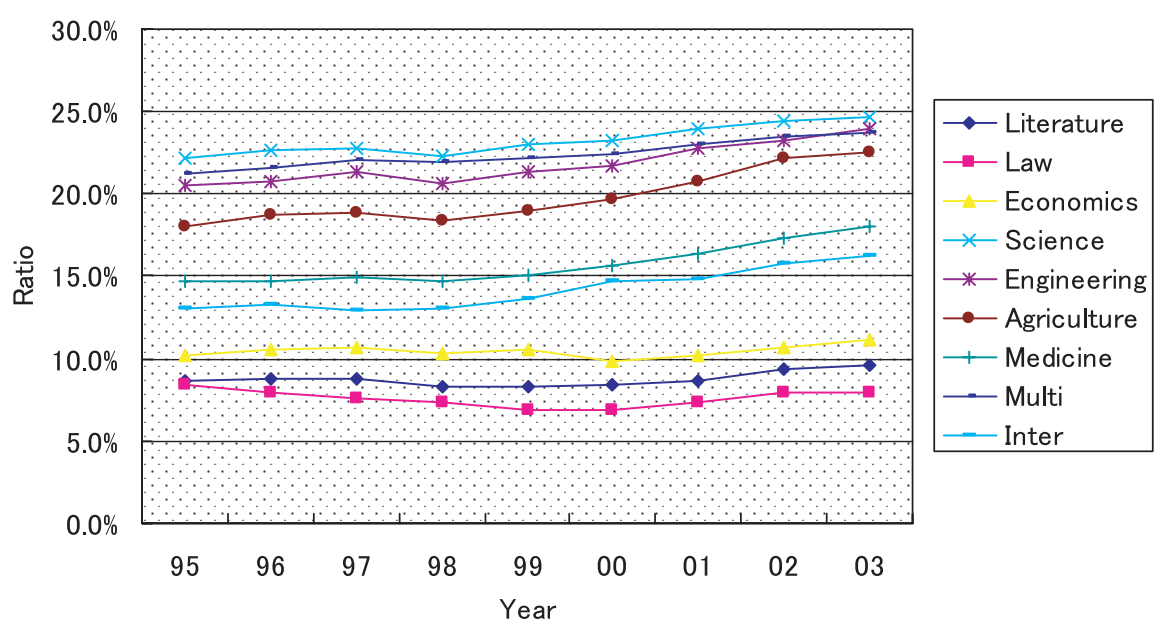

Fig. 18 Domestic joint research trend.

\subsubsection{Humanities and social sciences}

The significant necessity to facilitate humanities and social sciences was emphasized in the policy. It is often pointed out that the results of research activities in these fields were not fully utilized in society and policy making. The Science Council stated that research activities in these fields constitute the base of the social system and that its importance should be recognized as well as that of the natural sciences, except for what tends to be influenced by financial situations, such as institutions and equipment, by these measures.

Whereas the national plan states the importance of these areas, it is hard to say that the situation of humanities and social sciences has improved. In actuality, in the humanities and social sciences areas, literature, law, and economics, the number of $\mathrm{PhD}$. students even 
International Joint Research

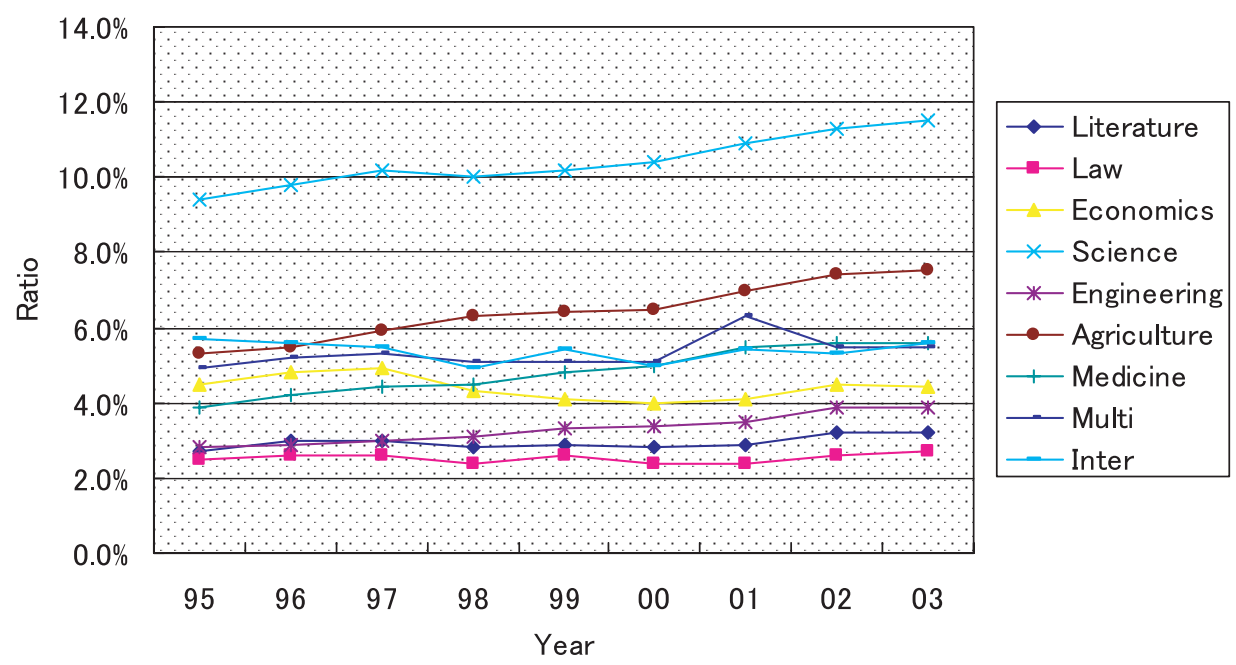

Fig. 19 International joint research trend.

decreased a little in 2001, as compared to 1998. It can be said that the cultivation of these researchers and the training of younger researchers is seldom progressing.

Most of the academic institutions and researchers in Japan could be in a transition period. The government and councils have known about the data presented in this paper and pointed out a lot of the problems. However, many of them have hardly been solved, so that the problems are reproduced. Keeping a financial base for research activities may be getting more and more important for each research institution. However, without continuing basic activities at academic institutions, such as cultivating younger researchers, quality of academic research might decline.

It is said that the Industry-University collaboration is the strongest method for promoting creativity in R\&D activities. So, this is a splendid opportunity for various researchers to meet and exchange their knowledge and experiences. In 1998 the "NPO Law" was enacted for the promotion of private non-profit organization contributing to societal activities by citizens. After that, over 20,000 organizations were authorized as juristic bodies by the government. The author feels that Non-Profit Organization-University collaboration is a breakthrough for humanities and social sciences, because such collaborations were successful before. It is necessary to plan a system to make effective collaborations between universities and public organizations and public-service corporations.

In conclusion, the Japanese government and Science councils have worked since the early 90's to promote more academic research activities. However, their plans were still so ineffective that the Science council of
Japan submitted a proposal before the third term of the plan had started. A lot of goals had been presented, but the degrees of achievement have not been confirmed for each by the end of the term. When compared with other countries, too much value has been put on developing new technology or materials that are applicable for the commercial industry in Japan.

In 2003 the National University Reform Bills, written to help transform "national universities" into "independent administrative organization" in April 2004 were enacted. Traditional universities are obliged to focus on developmental research, patents and marketing. Furthermore, corporate researchers are allowed to apply for governmental Grant-in-Aid for Scientific Research. These tendencies will bring a paradigm shift to the evaluation system in research activities.

\section{Acknowledgements}

I wish to thank Moe Igari for her critical contribution to this study.

\section{References}

[1] Science Division, Minister of Education, Science and Culture of Japan, "Comprehensive Promotion Measures for Science Research on the Brink of the 21st Century," Japanese Science Monthly, Japan Society for the Promotion of Science, vol.45, no.8, pp.69-90, 1992 (in Japanese).

[2] "Data of Statistics Bureau" in Ministry of Education, Sports, Culture, Science and Technology, "White Paper on Science and Technology Paper, FY2005," pp.344375, 2005 (in Japanese). http://www.mext.go.jp/b_menu/houdou/17/06/ 
05060903/041.pdf

[3] Y. Ohtawa, S. Kakinuma, M. Nishizawa, and Y. Sun, "Academic research activities in Japan: A report on the 1993 academic research activities survey," J. Information Management, vol.39, no.7, pp.483-509, 1996 (in Japanese).

[4] Y. Ohtawa, S. Kakinuma, M. Nishizawa, Y. Sun, and Y. Yamashita, "Academic research activities in Japan: A summary report on the 1995 Academic Research Activities Survey," J. Information Management, vol.40, no.9, pp.770-789, 1997 (in Japanese).

[5] National Center for Science Information Systems, "Academic Research Activities in Japan: A Report on the 1996 Academic Research Survey," pp.1-42, 1998 (in Japanese).

[6] National Center for Science Information Systems, "Academic Research Activities in Japan: A Report on the 1997 Academic Research Survey," pp.1-42, 1999 (in Japanese).

[7] National Center for Science Information Systems, "Academic Research Activities in Japan: A Report on the 1998 Academic Research Survey," pp.1-43, 2000 (in Japanese).

[8] National Institutes of Informatics, "Academic Research Activities in Japan: A Report on the 1999 Academic Research Survey,” pp.1-43, 2001 (in Japanese).

[9] National Institutes of Informatics, "Academic Research Activities in Japan: A Report on the 2000 Academic Research Survey,” pp.1-43, 2002 (in Japanese).

[10] National Institutes of Informatics, "Academic Research Activities in Japan: A Report on the 2001 Academic Research Survey," pp.1-43, 2003 (in Japanese).

[11] National Institutes of Informatics, "Academic Research
Activities in Japan: A Report on the 2002 Academic Research Survey," pp.1-43, 2004 (in Japanese).

[12] National Institutes of Informatics, "Academic Research Activities in Japan: A Report on the 2003 Academic Research Survey," pp.1-43, 2005 (in Japanese).

[13] Y. Sun, Y. Yamashita, M. Nishizawa, S. Kakinuma, and M. Negishi, "Number of Paper and Article Citing in Japan: a Statistical Analysis using ISI Citation Database," NACSIS, pp.15-27, 1999 (in Japanese).

[14] Science and Technology Agency, "Science and Technology White Paper, FY1999," 1999.

[15] M. Shibayama and M. Yano, "R\&D Activity in Japanese Companies and Universities" in "Cross-Cultural Innovation - Results the 8th European Conference on Creativity and Innovation-," Deustcher UniversitaetsVerlag, p.523, 2004.

[16] M. Shibayama and M. Igari, "Analysis on Researchers in Japanese Academic Institutes During 1993-2001," NII Technical Report NII-2005-001J, 2005 (in Japanese).

http://research.nii.ac.jp/TechReports/05-001J-j.htm

[17] Science and Technology Agency, "Science and Technology Indicators, FY1999," 1999 (in Japanese).

[18] Science and Technology Agency, "Science and Technology Indicators, FY2000," 2000 (in Japanese).

[19] Ministry of Education, Sports, Culture, Science and Technology Agency, "White Paper on Science and Technology, FY2002," 2002 (in Japanese).

[20] Ministry of Education, Sports, Culture, Science and Technology Agency, "White Paper on Science and Technology, FY2005,” pp.1-42, 2005 (in Japanese). http://www.mext.go.jp/english/news/2005/04/ 05051301.htm 


\section{Appendix}

1) The research classification is accordance with Japanese Grants-in-aid for Scientific Research.

2) Interdisciplinary means a wider category than Multidisciplinary, which is made of over two fields.

\begin{tabular}{ll}
\hline Field & Disciplines \\
\hline Humanities & $\begin{array}{l}\text { Literature \& Language, History, Philosophy \& Religion, Psychology, Sociology, Education, } \\
\text { and Cultural Anthropology }\end{array}$ \\
\hline Law & Law, and Political Science \\
\hline Economics & Economics, Finance, Management, and Accounting \\
\hline Science & Mathematics, Physics, Chemistry, Biology, and Earth Science \\
\hline Engineering & $\begin{array}{l}\text { Applied Physics, Mechanics, Electronics, Construction Engineering, Material Engineering, } \\
\text { and Chemical Engineering }\end{array}$ \\
\hline Agriculture & Agriculture, Forestry, Fishery, Veterinary Sciences, and Food Sciences \\
\hline Medicine & Clinical Medicine, Public Health, Pharmacy, Dentistry, and Nursing \\
\hline Multidisciplinary & $\begin{array}{l}\text { Geography, Information Science, Biochemistry, Basic Biology, Energy Sciences, Environ- } \\
\text { ment Sciences, Neurology Sciences, History of Science, and Social Engineering }\end{array}$ \\
\hline Interdisciplinary & General, and Combination of upper fields \\
\hline
\end{tabular}

\section{Morio SHIBAYAMA}

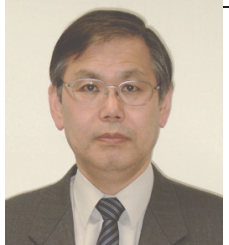

Morio Shibayama received B.E. and M.E. degrees from University of Tokyo in 1975 and 1977, respectively. He is an associate professor, Research Information Research Division, National Institutes of Informatics. His current researches are evaluation of research, survey of research environment and identification of creativity in research activities. 